\title{
Peran Kompetensi, Motivasi dan Kepemimpinan Dalam Peningkatan Kinerja Pegawai
}

\author{
I Gede Ngurah Astawan ${ }^{(1)}$ \\ I Gusti Ngurah Putra Suryanata ${ }^{(2)}$ \\ Staf Keuangan RSUP Sanglah Denpasar ${ }^{(1)}$ \\ Universitas Pendidikan Nasional ${ }^{(2)}$ \\ gede.ngurahastawan@gmail.com ${ }^{(1)}$ \\ ngurahputrasuryanata@undiknas.ac.id ${ }^{(2)}$
}

\begin{abstract}
The hospital is a capital intensive organization, full of human resources, solid technology and science, and regulation intensive. Solid capital because it requires a high investment to meet the requirements of both physical buildings and other supporting facilities and infrastructure, especially existing health equipment. Solid human resources because in hospitals work a variety of professionals / multidisciplinary with a large number of employees and demanded harmonious cooperation between professionals (team work) to create quality services. Health care providers in the world of health business are increasingly guided to be able to help fast and encouraged services capable of always developing and adapting to changes to win the competition. The purpose of this study is 1) To analyze and explain the influence of leadership, competence, motivation on employee performance and the role of variable motivation to work motivation. The method used in this study is a quantitative method with path analysis techniques. The results of the study show that 1) The competence on leadership in the Amerta Wing Installation of Sanglah Hospital Denpasar is equal to 0.270;2) The direct influence of competence on leadership is at the Amerta Wing Installation in Sanglah Hospital, Denpasar, at 0.484; 3) Direct influence of leadership on employee performance at the Amerta Wing Installation at Sanglah Hospital Denpasar, amounting to 0.298; 4) The indirect effect of work motivation on performance in the Amerta Wing Installation at Sanglah Hospital Denpasar is equal to 0.080 ; 5) The indirect effect of competence on performance in the Amerta Wing Installation of Sanglah Hospital Denpasar is equal to 0.144; 6) The leadership role in mediating the influence of leadership on the performance of employees at the Amerta Wing Installation in RSUP Sanglah Denpasar shows that getting t count is $=0.208$, and is significant with a value of $0.417>0.05$ so it can be concluded that there is insignificant positive influence mediating work motivation between the influence of leadership on employee performance; and 7) The role of motivation in mediating the influence of competencies on employee performance at the Amerta RSUP Sanglah Denpasar Upper Installation shows that getting t count is $=0.207$ and is significant with a value of $0.417>0.05$ so it can be concluded that there is no positive effect significant mediation of work motivation between the effect of work competency on employee performance.
\end{abstract}

Keywords: leadership; competence; motivation; performance 
Rumah sakit merupakan organisasi yang padat modal, padat sumber daya manusia, padat teknologi dan ilmu pengetahuan serta padat regulasi. Padat modal karena memerlukan investasi yang tinggi untuk memenuhi persyaratan baik bangunan fisik maupun sarana dan prasarana penunjang lainnya terutama peralatan kesehatan yang ada. Padat sumber daya manusia karena di rumah sakit bekerja berbagai profesional/multidisiplin dengan jumlah karyawan yang banyak serta dituntut adanya kerjasama yang harmonis antar profesional (team work) untuk mewujudkan pelayanan yang berkualitas. Penyedia layanan kesehatan dalam dunia bisnis kesehatan semakin dituntun dapat membantu pelayanan yang cepat dan didorong mampu untuk selalu berkembang dan beradaptasi dengan perubahan untuk dapat memenangkan persaingan. Tujuan dari penelitian ini adalah 1) Untuk menganalisis dan manjelaskan pengaruh kepemimpinan, kompetensi, motivasi terhadap kinerja pegawai dan peran variabel mediasi motivasi kerja. Metode yang digunakan dalam penelitian ini adalah metode kuantitatif dengan teknik analisis path. Adapun hasil penelitian menunjukkan bahwa 1) Pengaruh langsung kompetensi (KOMP) terhadap kepemimpinan di Instalasi Wing Amerta RSUP Sanglah Denpasar adalah sebesar 0,270;2) Pengaruh langsung kompetensi terhadap kepemimpinan adalah di Instalasi Wing Amerta RSUP Sanglah Denpasar sebesar 0,484; 3) Pengaruh langsung kepemimpinan terhadap kinerja pegawai di Instalasi Wing Amerta RSUP Sanglah Denpasar adalah sebesar 0,298; 4) Pengaruh tidak langsung motivasi kerja terhadap kinerja di Instalasi Wing Amerta RSUP Sanglah Denpasar adalah sebesar 0,080; 5) Pengaruh tidak langsung kompetensi terhadap kinerja di Instalasi Wing Amerta RSUP Sanglah Denpasar adalah sebesar 0,144 ; 6) Peran kepemimpinan dalam memediasi pengaruh kepemimpinan terhadap kinerja pegawai di Instalasi Wing Amerta RSUP Sanglah Denpasar menunjukkan bahwa mendapatkan $\mathrm{t}$ hitung sebesar $=0,208$, dan signifikan dengan nilai $0.417>0.05$ maka dapat disimpulkan bahwa ada pengaruh positif yang tidak signifikan mediasi motivasi kerja antara pengaruh kepemimpinan terhadap kinerja pegawai; dan 7) Peran motivasi dalam memediasi pengaruh kompetensi terhadap kinerja pegawai di Instalasi Wing Amerta RSUP Sanglah Denpasar atas menunjukkan bahwa mendapatkan t hitung sebesar $=0,207$, dan signifikan dengan nilai $0.417>0.05$ maka dapat disimpulkan bahwa ada pengaruh positif tidak signifikan mediasi motivasi kerja antara pengaruh kopetensi kerja terhadap kinerja pegawai.

\section{Kata kunci : kepemimpinan; kompetensi; motivasi; kinerja}




\section{PENDAHULUAN}

Rumah sakit merupakan organisasi yang padat modal, padat sumber daya manusia, padat teknologi dan ilmu pengetahuan serta padat regulasi (Winarta dan Darma, 2018). Padat modal karena memerlukan investasi yang tinggi untuk memenuhi persyaratan baik bangunan fisik maupun sarana dan prasarana penunjang lainnya terutama peralatan kesehatan yang ada (Dewi dan Darma, 2019). Padat sumber daya manusia karena di rumah sakit bekerja berbagai profesional/multidisiplin dengan jumlah karyawan yang banyak (Halim dan Darma, 2019; Hendhana dan Darma, 2017) serta dituntut adanya kerjasama yang harmonis antar profesional (team work) untuk mewujudkan pelayanan yang berkualitas. Penyedia layanan kesehatan dalam dunia bisnis kesehatan semakin dituntun dapat membantu pelayanan yang cepat dan didorong mampu untuk selalu berkembang dan beradaptasi dengan perubahan untuk dapat memenangkan persaingan (Setyawati dan Darma, 2018).

Sistem pelayanan kesehatan di Rumah Sakit yang mempunyai fungsi menjaga mutu pelayanan, yang sering dijadikan barometer oleh masyarakat, dalam menilai mutu rumah sakit, sehingga menuntut adanya profesionalisme pegawai dalam bekerja yang ditunjukkan oleh hasil kinerja pegawai. Sebagai institusi kesehatan dituntut untuk selalu meningkatkan kinerja pegawai, agar dapat terus bertahan dan berkembang. Salah satunyan adalah pelayanan di Instalasi Wing Amerta merupakan Instalasi di RSUP Sanglah Denpasar yang memiliki pelayanan sepesialis.

RSUP Sanglah dapat diketahui bahwa walaupun berbagai upaya telah dilakukan oleh RSUP Sanglah dalam rangka mewujudkan Visi, Misi, serta tujuannya, namun masih banyak mendapat sorotan, kritik, dan saran dari masyarakat, atas ketidakpuasan pelanggan terhadap pelayanan RSUP Sanglah. Salah satu kegiatan yang mendukung pelayanan kesehatan adalah pada Direktorat Pelayanan Medik dan Keperawatan beserta Instalasinya sebagai penunjang pelayanan dalam memenuhi kebutuhan masyarakat akan pelayanan kesehatan melakukan pengembangan sarana fisik, penambahan fasilitas/ perlengkapan terus dilakukan, penataan lingkungan yang begitu pesat, namun pengembangan fasilitas dan prasarana tidak didukung peningkatan kualitas sumber daya manusia untuk memenuhi kebutuhan pengembangan tersebut.

Peningkatan kinerja pegawai akan membawa kemajuan bagi Institusi untuk dapat bertahan dalam melakukan pelayanan terhadap masyarakat (Widiastra dan Darma, 2015). Oleh karena itu upaya-upaya untuk meningkatkan kinerja karyawan merupakan tantangan pemimpin yang paling serius karena keberhasilan untuk mencapai tujuan tergantung pada 
kualitas kinerja sumber daya manusia yang ada didalamnya (Yudiastra dan Darma, 2015). Pada periode 2013 hingga 2017 mengalami penurunan tiap tahunnya, salah satu faktor yang mempengaruhi menurunnya kunjungan pasien adanya regulasi paskes BPJS, adanya kekurangan-kekurangan yang terjadi dalam pelaksanaan pelayanan kesehatan di Instalasi Wing Amerta seperti lamanya dokter sepesialis yang dihubungi, dokter datang terlambat dari waktu yang dijanjikan, alat-alat bantu diagnosis yang tidak berfungsi sebagaimana mestinya sehingga menghambat proses diagnosis, persediaan obat yang tidak lengkap, tingkat kunjungan pasien cendrung menurun. kinerja pegawai cendrung belum maksimal, serta menurunnya kunjungan pasien di rawat jalan Wing Amerta sehingga perlu adanya inovasi pelayanan kesehatan melalui peningkatan kinerja pegawai. Dari fenomena yang terjadi di rumah sakit yang menunjukkan bahwa kinerja pegawai belum maksimal sehingga perlu di ketahui faktor yang menyebabkan menurunnya kinerja karyawan.

\section{Kompetensi}

Menurut Widiari dan Darma (2019) definisi konseptual dari kompetensi seseorang menunjukkan pada kekuatan yang ada pada pekerjaan atau kemampuan dan kematangan psikologi yang dapat mengarahkan perilaku diri sendiri. Dari segi etimologi, kompetensi berarti segi keunggulan, keahlian dari perilaku seseorang pegawai atau pemimpin yang mana punya suatu pengetahuan, perilaku dan ketrampilan yang baik. Karakteristik dari kompetensi yaitu sesuatu yang menjadi bagian dari karakter pribadi dan menjadi bagian dari prilaku seseorang dalam melaksanakan suatu tugas pekerjaan (Mangkunegara, 2007; Widiari dan Darma, 2019).

\section{Motivasi}

Motivasi yaitu kesediaan untuk mengeluarkan tingkat upaya yang tinggi untuk tujuan organisasi yang dikondisikan oleh kemampuan upaya itu untuk memenuhi beberapa kebutuhan individu (Robbins, 2001; Widiatmika dan Darma, 2018). Mangkunegara (2007), yaitu bahwa motivasi sebagai suatu kondisi yang menggerakan manusia ke arah suatu tujuan tertentu. Dalam hubungannya dengan motivasi kerja, bahwa motivasi kerja didefinisikan sebagai suatu kondisi yang berperan dalam menggerakkan, mengarahkan dan memelihara prilaku yang berhubungan dengan motivasi kerja.

\section{Kepemimpinan}

Kepemimpinan itu adalah cara seorang pemimpin mempengaruhi prilaku bawahan, agar mau bekerja sama dan bekerja secara produktif untuk mencapai tujuan organisasi. 
Kepemimpinan adalah cara seorang pemimpin mempengaruhi perilaku bawahan agar mau bekerja sama dan bekerja secara efektif dan efisien untuk mencapai tujuan organisasi (Hasibuan, 2014; Wiandari dan Darma, 2017).

\section{Kinerja}

Kinerja adalah singkatan dari energi kerja, dalam bahasa Inggris adalah performance. Pengertian kinerja merupakan hasil atau keluaran yang dihasilkan oleh fungsi-fungsi atau indikator-indikator suatu pekerjaan atau suatu profesi dalam kurun waktu tertentu (Kurniadi, 2013). Kinerja keperawatan adalah prestasi kerja yang ditunjukkan oleh perawat pelaksana dalam melaksanakan tugas-tugas asuhan keperawatan sehingga menghasilkan output yang baik kepada customer (organisasi, klien, perawat sendiri) dalam kurun waktu tertentu. Tanda - tanda kinerja perawat yang baik adalah tingkat kepuasan klien dan perawat tinggi,zero complain dari pelanggan (Kurniadi, 2013; Dewi dan Darma, 2017).

\section{Kerangka Pemikiran}

Konsep penelitian merupakan hubungan logis dari landasan teoritis dan kajian empiris yang telah dijelaskan pada bagian sebelumnya. Berdasarkan rumusan masalah dan kerangka berpikir dalam penelitian ini yang menjadi variable bebas adalah Kepemimpinan (X1) dan Motivasi (X2), Kompetensi(Y1) dan kinerja (Y2). Sesuai dengan jumlah variabel yang teridentifikasi kerangka berpikir yang telah dijelaskan sebelumnya, kemudian disusun konsep yang menjelaskan hubungan antar variable dalam penelitian ini konsep tersebut disajikan pada gambar di bawah ini.

Kerangka Konsep Penelitian

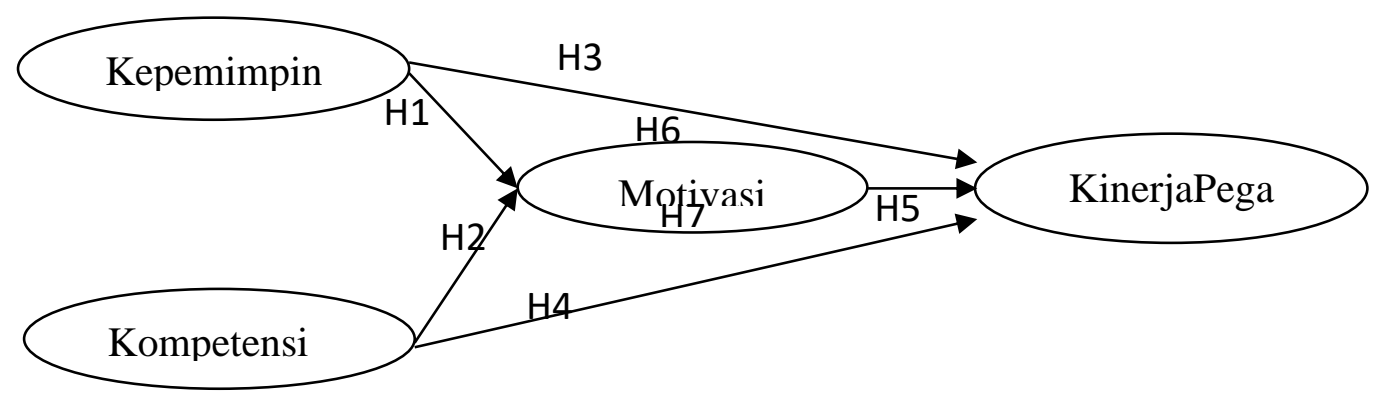

Gambar 1. Kerangka Konsep Penelitian 


\section{Hipotesis Penelitian}

H1 : Kepemimpinan berpengaruh positif dan signifikan terhadap motivasi kerja.

H2 : Kompetensi berpengaruh positif dan signifikan terhadap motivasi Kerja.

H3 : Kepemimpinan berpengaruh positif dan signifikan terhadap kinerja pegawai.

H4 : Kompetensi berpengaruh positif dan signifikan terhadap kinerja pegawai.

H5 : Motivasi berpengaruh positif dan signifikan terhadap kinerja pegawai.

H6 : Motivasi memediasi pengaruh kepemimpinan terhadap kinerja pegawai.

H7 : Motivasi memediasi pengaruh kompetensi terhadap kinerja pegawai.

\section{METODE PENELITIAN}

Dalam penelitian ini menggunakan metode penelitian kuantitatif, adapun teknik analisis yang digunakan dalam penelitian adalah path analysis dan untuk mengetahui peran variabel mediasi menggunkan sobeltest. Berdasarkan jumlah populasi yang terdapat pada Instalasi Wing Amerta RSUP Sanglah Denpasar yang digunakan adalah sampel. Tekhnik pengambilan sampel dalam penelitian ini adalah dengan menggunakan tekhnik sensus. Digunakan tekhnik ini karena populasi yang akan diteliti kurang dari 100 (seratus) orang sehingga sampel yang diambil dari keseluruhan populasi yang ada di Instalasi Wing Amerta RSUP Sanglah Denpasar sejumlah 50 orang.

\section{PEMBAHASAN}

Dalam analisis ini dilakukan perbandingan koefisien korelasi (Corrected Item-Total Correlation) hasil pengolahan. SPSS for Windows versi 23.0 dengan koefisien korelasi product momen tabel. Pertanyaan dinyatakan valid, apabila koefisien Corrected Item-Total Correlation hasil perhitungan lebih besar dari koefisien korelasi dalam table nilai kritis pada derajat bebas yang bersesuaian ( $r_{\text {hitung }}>r_{\text {tabel }}$ ). Adapun hasil analisis uji validitas seperti tabel berikut ini

Tabel 1. Uji Validitas

\begin{tabular}{|c|c|c|c|c|}
\hline No & Butir & $\begin{array}{c}\mathrm{r}_{\text {hitung }} \\
\text { (Corrected Item-Total } \\
\text { Correlation })\end{array}$ & $\mathrm{r}_{\text {tabel }}$ & Keterangan \\
\hline 1 & komp1 & 0,482 & 0,306 & $\mathrm{r}_{\text {hitung }}>\mathrm{r}_{\text {tabel; Valid }}$ \\
2 & komp2 & 0,764 & 0,306 & $\mathrm{r}_{\text {hitung }}>\mathrm{r}_{\text {tabel; Valid }}$ \\
3 & komp3 & 0,581 & 0,306 & $\mathrm{r}_{\text {hitung }}>\mathrm{r}_{\text {tabel; Valid }}$ \\
4 & komp4 & 0,501 & 0,306 & $\mathrm{r}_{\text {hitung }}>\mathrm{r}_{\text {tabel; Valid }}$ \\
5 & komp5 & 0,534 & 0,306 & $\mathrm{r}_{\text {hitung }}>\mathrm{r}_{\text {tabel; Valid }}$ \\
\hline 1 & mot1 & 0,588 & 0,306 & $\mathrm{r}_{\text {hitung }}>\mathrm{r}_{\text {tabel; Valid }}$ \\
2 & $\operatorname{mot} 2$ & 0,575 & 0,306 & $\mathrm{r}_{\text {hitung }}>\mathrm{r}_{\text {tabel; Valid }}$ \\
3 & $\operatorname{mot3}$ & 0,368 & 0,306 & $\mathrm{r}_{\text {hitung }}>\mathrm{r}_{\text {tabel; Valid }}$ \\
\hline
\end{tabular}




\begin{tabular}{|c|c|c|c|c|}
\hline 4 & $\operatorname{mot} 4$ & 0,768 & 0,306 & $\mathrm{r}_{\text {hitung }}>\mathrm{r}_{\text {tabel; }}$ Valid \\
\hline 5 & $\operatorname{mot} 5$ & 0,574 & 0,306 & $\mathrm{r}_{\text {hitung }}>\mathrm{r}_{\text {tabel; }}$ Valid \\
\hline 6 & mot6 & 0,431 & 0,306 & $r_{\text {hitung }}>r_{\text {tabel; }}$ Valid \\
\hline 7 & $\operatorname{mot} 7$ & 0,630 & 0,306 & $\mathrm{r}_{\text {hitung }}>\mathrm{r}_{\text {tabel; }}$ Valid \\
\hline 8 & $\operatorname{mot} 8$ & 0,392 & 0,306 & $\mathrm{r}_{\text {hitung }}>\mathrm{r}_{\text {tabel; }}$ Valid \\
\hline 9 & $\operatorname{mot} 9$ & 0,460 & 0,306 & $\mathrm{r}_{\text {hitung }}>\mathrm{r}_{\text {tabel }}$ V Valid \\
\hline 1 & kep1 & 0,508 & 0,306 & $r_{\text {hitung }}>r_{\text {tabel; }}$ Valid \\
\hline 2 & kep2 & 0,719 & 0,306 & $r_{\text {hitung }}>r_{\text {tabel}} ;$ Valid \\
\hline 3 & kep3 & 0,610 & 0,306 & $r_{\text {hitung }}>r_{\text {tabel; }}$ Valid \\
\hline 4 & kep4 & 0,548 & 0,306 & $r_{\text {hitung }}>r_{\text {tabel}} ;$ Valid \\
\hline 1 & kin1 & 0,492 & 0,306 & $r_{\text {hitung }}>r_{\text {tabel; }}$ Valid \\
\hline 2 & kin2 & 0,548 & 0,306 & $r_{\text {hitung }}>r_{\text {tabel; }}$ Valid \\
\hline 3 & $\operatorname{kin} 3$ & 0,555 & 0,306 & $r_{\text {hitung }}>r_{\text {tabel; }}$ Valid \\
\hline 4 & kin4 & 0,606 & 0,306 & $r_{\text {hitung }}>r_{\text {tabel; }}$ Valid \\
\hline 5 & kin5 & 0,414 & 0,306 & $r_{\text {hitung }}>r_{\text {tabel; }}$ Valid \\
\hline
\end{tabular}

Sumber : data diolah, 2019

Dari Tabel di atas dapat diketahui seluruh butir pertanyaan variabel adalah valid.

\section{Uji Reliabilitas}

Dalam analisis ini dilakukan perbandingan Cronbach's Alpha (koefisien hitung reliabilitas alpha) seluruh butir pertanyaan kompensasi hasil pengolahan dengan nilai 0,60. Dari pengolahan SPSS for Windows versi 23.0 didapat koefisien Cronbach's Alpha (koefisien hitung reliabilitas alpha) seperti table berikut.

Tabel 2

\begin{tabular}{|l|l|}
\hline Variabel & Cronbach's Alpha \\
\hline Kompetensi & 0,787 \\
\hline Motivasi & 0,824 \\
\hline Kepemimpinan & 0,777 \\
\hline Kinerja & 0,753 \\
\hline
\end{tabular}

Sumber : data diolah, 2019

Dari tabel di atas, terlihat besarnya koefisien Cronbach's Alpha (koefisien hitung reliabilitas alpha) setiap variabel besarnya di atas 0,60 berarti bahwa pertanyaan (kuesioner) seluruh variabel adalah reliabel. 


\section{Analisis Pengaruh dengan Path Analysis}

Path Analysis Pengaruh kepemimpinan, kompetensi, motivasi kerja terhadap kinerja pegawai di Instalasi Wing Amerta RSUP Sanglah Denpasar

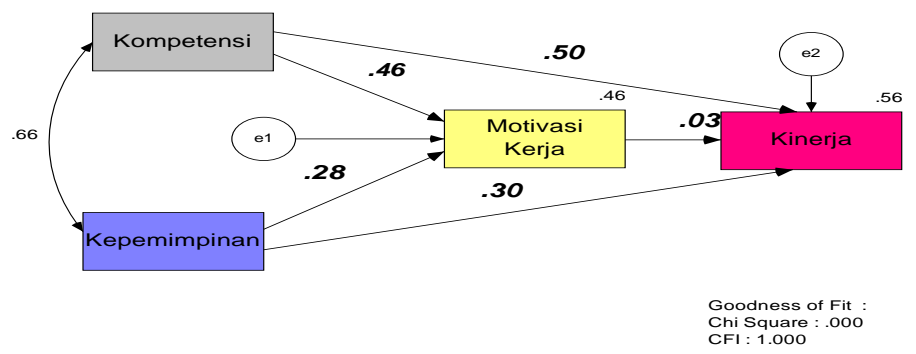

Gambar 2

Path Analysis Antar Variabel

Kepemimpinan, Kompetensi, Motivasi Kerja Dan Kinerja Pegawai Di Instalasi Wing Amerta RSUP Sanglah Denpasar

Dari gambar diatas dapat diperoleh informasi besarnya koefisien Regression Weight untuk masing-masing variabel seperti pada tabel 5 dibawah ini:

Tabel 5

Regression Weight Path Analysis

\begin{tabular}{|c|c|c|c|c|c|c|}
\hline & $\begin{array}{r}\text { Unstandardized } \\
\text { Estimate }\end{array}$ & $\begin{array}{r}\text { Standardized } \\
\text { Estimate }\end{array}$ & S.E. & C.R. & $\mathrm{P}$ & Ket \\
\hline MOT <--- KOMP & .859 & .459 & .261 & 3.286 & .001 & Signifikan \\
\hline MOT <--- KEP & .746 & .280 & .373 & 2.001 & .045 & Signifikan \\
\hline KIN <--- KOMP & .479 & .495 & .135 & 3.543 & $* * *$ & Signifikan \\
\hline$<---\quad$ KEP & 411 & 298 & .182 & 2.261 & .024 & Signifikan \\
\hline KIN <--- MOT & 014 & .027 & .067 & .205 & .837 & $\begin{array}{l}\text { Tidak } \\
\text { Signifikan }\end{array}$ \\
\hline
\end{tabular}

Sumber : data diolah, 2019

Berdasarkan hasil analisis Path Analysis di atas, baik dalam bentuk diagram maupun dalam bentuk tabel, diketahui bahwa koefisien Standardized Regression Weight untuk semua variabel berpengaruh positif. Pengaruh positif yang paling besar adalah variabel kompetensi (KOMP) terhadap kinerja (KIN) memiliki standardized estimate (regression weight) sebesar 0,495, dengan $\mathrm{Cr}$ (Critical ratio = identik dengan nilai t-hitung) sebesar 3,543 pada probability ***. Nilai CR 3,543 > 2,000 dan Probability $=* * *<0,05$ menunjukkan bahwa pengaruh variabel laten kompetensi (KOMP) terhadap variabel laten kinerja (KIN) adalah positif signifikan.

Pengaruh positif variabel kompetensi (KOMP) terhadap motivasi kerja (MOT) memiliki standardized estimate (regression weight) sebesar 0,459, dengan $\mathrm{Cr}($ Critical ratio $=$ identik dengan nilai t-hitung) sebesar 3,286 pada probability 0,001. Nilai CR 3,286 > 2,000 
dan Probability $=0,001<0,05$ menunjukkan bahwa pengaruh variabel laten kompetensi (KOMP) terhadap variabel laten motivasi kerja (MOT) adalah positif signifikan.

Pengaruh variabel kepemimpinan (KEP) terhadap kinerja (KIN) memiliki standardized estimate (regression weight) sebesar 0,298, dengan $\mathrm{Cr}$ (Critical ratio = identik dengan nilai thitung) sebesar 2,261 pada probability 0,024. Nilai CR 2,261 > 2,000 dan Probability $=0,024$ $<0,05$ menunjukkan bahwa pengaruh variabel laten kepemimpinan (KEP) terhadap variabel laten kinerja (KIN) adalah positif signifikan.

Pengaruh variabel kepemimpinan (KEP) terhadap motivasi kerja (MOT) memiliki standardized estimate (regression weight) sebesar 0,280, dengan $\mathrm{Cr}$ (Critical ratio $=$ identik dengan nilai t-hitung) sebesar 2,001 pada probability 0,045. Nilai CR 2,001 > 2,000 dan Probability $=0,045<0,05$ menunjukkan bahwa pengaruh variabel laten kepemimpinan (KEP) terhadap variabel laten motivasi kerja (MOT) adalah positif signifikan.

Pengaruh variabel motivasi kerja (MOT) terhadap kinerja (KIN) memiliki standardized estimate (regression weight) sebesar 0,027, dengan $\mathrm{Cr}$ (Critical ratio $=$ identik dengan nilai thitung) sebesar 0,205 pada probability 0,837. Nilai CR 0,205 2,000 dan Probability $=0,837$ $>0,05$ menunjukkan bahwa pengaruh variabel laten motivasi kerja (MOT) terhadap variabel laten kinerja (KIN) adalah positif tidak signifikan.

\section{Pengaruh kepemimpinan, kompetensi, motivasi kerja terhadap kinerja pegawai di} Instalasi Wing Amerta RSUP Sanglah Denpasar

Untuk mengetahui pengaruh langsung variabel kepemimpinan, kompetensi, motivasi kerja terhadap kinerja pegawai di Instalasi Wing Amerta RSUP Sanglah Denpasar berdasarkan hasil pengolahan data dapat diketahui pada tabel 6 berikut.

Tabel 6

Pengaruh Langsung

Standardized Direct Effects (Group number 1-Default model)

\begin{tabular}{|l|rrr|}
\hline & KEP & KOMP & MOT \\
\hline MOT & .280 & .459 & .000 \\
KIN & .298 & .495 & .027 \\
\hline
\end{tabular}

Sumber : data diolah, 2019

Dari table di atas dapat diperoleh informasi pengaruh langsung sebagai berikut:

(1) Pengaruh langsung kepemimpinan (KEP) terhadap motivasi kerja (MOT) adalah sebesar 0,280 .

(2) Pengaruh langsung kompetensi (KOMP) terhadap motivasi kerja (MOT) adalah sebesar 0,459 . 
(3) Pengaruh langsung kepemimipinan (KEP) terhadap kinerja pegawai (KIN) adalah sebesar 0,298 .

(4) Pengaruh langsung kompetensi terhadap kinerja pegawai (KIN) adalah sebesar 0,495.

(5) Pengaruh langsung motivasi kerja (MOT) terhadap kinerja (KIN) adalah sebesar 0,027.

Besarnya pengaruh kompetensi, motivasi kerja, kepemimpinan dan kinerja pegawai di Instalasi Wing Amerta RSUP Sanglah Denpasar

Untuk menghitung besarnya persentase pengaruh kompetensi, motivasi kerja, kepemimpinan dan kinerja pegawai di Instalasi Wing Amerta RSUP Sanglah Denpasar digunakan koefisien Squared Multiple Correlations seperti tabel 7.

Tabel 7

Squared Multiple Correlations: (Group number 1 -Default model)

\begin{tabular}{|l|l|}
\hline & Estimate \\
\hline MOT & .458 \\
KIN & .555 \\
\hline
\end{tabular}

Sumber : data diolah, 2019

Tabel 7 menyatakan bahwa Square Multiple Correlation yang nilainya masing-masing sebesar 0,458 dan 0,555. Menurut Ferdinand, (2002 : 114) nilai Square Multiple Correlation untuk variabel kepemimpinan (KEP), kompetensi (KOMP), motivasi kerja (MOT), dan kinerja pegawai (KIN) identik dengan $\mathrm{R}^{2}$ pada SPSS. Square Multiple Correlation untuk kepemimpinan (KEP) sebesar 0,458, maka besarnya Determinasi adalah nilai Square Multiple Correlation untuk variabel motivasi kerja kali $100 \%=0,458 \times 100 \%=45,8 \%$. Dengan demikian dapat dinyatakan bahwa perubahan motivasi kerja (MOT) dipengaruhi oleh kepemimpinan dan kompetensi sebesar 45,8\%. Nilai Square Multiple Correlation untuk variabel kinerja pegawai (KIN) identik dengan $\mathrm{R}^{2}$ pada SPSS sebesar 0,555, maka besarnya Determinasi adalah nilai Square Multiple Correlation untuk variabel kinerja pegawai (KIN) kali $100 \%=0,555 \times 100 \%=55,5 \%$. Dengan demikian dapat dinyatakan bahwa perubahan kinerja pegawai (KIN) dipengaruhi oleh kepemimpinan, kompetensi, dan motivasi kerja sebesar $55,5 \%$.

Dari hasil penelitian menunjukkan bahwa adanya pengaruh kepemimpinan dan kompetensi terhadap motivasi dan kinerja sependapat dengan hasil penelitian yang dilakukan oleh (Zwel, 2000 dalam Wibowo, 2012), Jimat (2013), Triyanto (2014), Kumarawati (2017), Bagus (2012), Mudiarta (2012), Hamid (2012), Muobo(2013). 


\section{Uji Sobel}

Besarnya peran kepemimpinan dalam memediasi pengaruh motivasi terhadap. kinerja pegawai di Instalasi Wing Amerta RSUP Sanglah Denpasar

Sobeltest atau pengujian Sobel dilakukan dengan menggunakan aplikasi Daniel Soper dari situs $\underline{w w w . s o b e l t e s t d a n i e l s o p e r . c o m}$ dengan memasukkan hasil pengolahan data di atas $(\beta 1=$ $0,859)$ serta standard error $(0,261)$ dan $(\beta 3=0,014)$ serta standard error $(0,067)$ dapat dijelaskan pada gambar berikut ini :

\section{Gambar 3}

Hubungan Tidak Langsung Kepemimpinan Mempengaruhi Kinerja Pegawai Dengan Motivasi Kerja Sebagai Variabel Mediasi

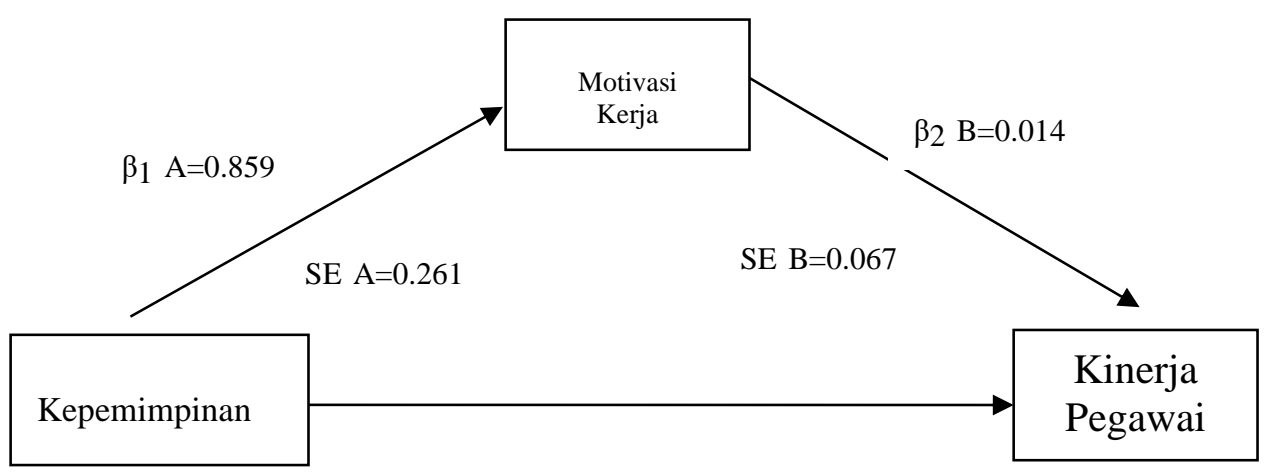

Sumber : data diolah, 2019

Hasil pengujian sobel di atas menunjukkan bahwa mendapatkan nilai $\mathrm{t}$ hitung sebesar = 0,208 dan signifikan dengan nilai $0.417>0.05$ maka dapat disimpulkan bahwa ada pengaruh positif yang tidak signifikan mediasi motivasi kerja antara pengaruh kepemimpinan terhadap kinerja pegawai tidak teruji kebenarannya. Artinya kepemimpinan secara tidak langsung tidak mampu memberikan perubahan terhadap kinerja namun harus melalui motivasi kerja terlebih dahulu.

\section{Peran kompetensi dalam memediasi pengaruh motivasi kerja terhadap kinerja pegawai di Instalasi Wing Amerta RSUP Sanglah Denpasar}

Sobeltest atau pengujian Sobel dilakukan dengan menggunakan aplikasi Daniel Soper dari situs WwW.sobeltestdanielsoper.com dengan memasukkan hasil pengolahan data di atas $(\beta 3=0,746)$ serta standard error $(0,373)$ dan $(\beta 4=0,014)$ serta standard error $(0,067)$ dapat dijelaskan pada gambar berikut ini : 


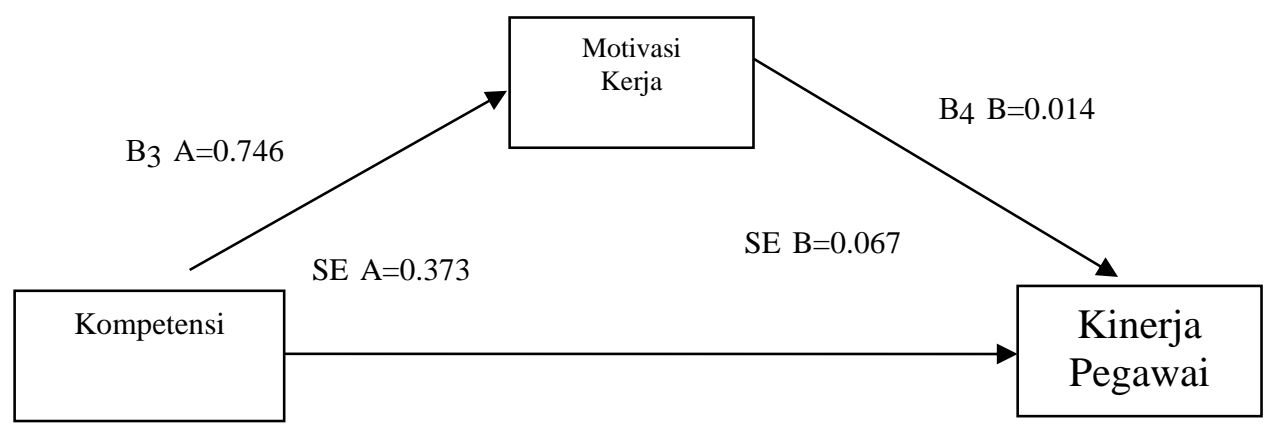

Gambar 4.9

Hubungan Tidak Langsung Kompetensi Mempengaruhi Kinerja Pegawai Dengan Motivasi Kerja Sebagai Variabel Mediasi

Sumber : data diolah, 2019

Hasil pengujian sobel di atas menunjukkan bahwa mendapatkan nilai thitung sebesar $=0,207$, dan signifikan dengan nilai $0.417>0.05$ maka dapat disimpulkan bahwa ada pengaruh positif tidak signifikan mediasi motivasi kerja antara pengaruh kopetensi kerja terhadap kinerja pegawai tidak teruji kebenarannya. Artinya kompetensi secara tidak langsung belum mampu memberikan perubahan terhadap kinerja namun harus melalui motivasi kerja terlebih dahulu.

Hasil pengujian peran mtoviasi sebagai variabel mediasi untuk kepemimpinan tidak signifikan tidak sesuai dengan penelitian yang dikemukakan oleh Mondiani (2012), Yudistira (2012), penelitian Kumarawati (2017), sedangkan peran variabel mediasi untuk kompetensi terhadap kinerja menunjukkan bahwa sesuai dengan penelitian yang dikemukakan oleh Mashuri (2014).

\section{PENUTUP}

Berdasarkan tujuan penelitian, hasil pengumpulan data dan hasil analisis data tentang kompetensi, motivasi kerja dan kepemimpinan terhadap kinerja pegawai di Instalasi Wing Amerta RSUP Sanglah Denpasar, dapat ditarik kesimpulan: Pengaruh variabel kepemimpinan terhadap motivasi kerja memiliki standardized estimate (regression weight) sebesar 0,280, dengan Cr (Critical ratio = identik dengan nilai t-hitung) sebesar 2,001 pada probability 0,045. Nilai CR 2,001 $>2,000$ dan Probability $=0,045<0,05$ menunjukkan bahwa pengaruh variabel laten kepemimpinan terhadap variabel laten motivasi kerja adalah positif signifikan sesuai dengan hipotesis yang diajukan sehingga teruji tingkat kebenarannya. Adanya pengaruh positif kepemimpinan terhadap motivasi berarti secara nyata variabel kepemimpinan mampu memberikan perubahan atau peningkatan secara nyata terhadap variabel motivasi di Instalasi Wing Amerta RSUP Sanglah Denpasar. Pengaruh variabel 
kompetensi terhadap motivasi kerja memiliki standardized estimate (regression weight) sebesar 0,459, dengan $\mathrm{Cr}$ (Critical ratio = identik dengan nilai t-hitung) sebesar 3,286 pada probability 0,001. Nilai CR 3,286 $>2,000$ dan Probability $=0,001<0,05$ menunjukkan bahwa pengaruh variabel laten kompetensi terhadap variabel laten motivasi kerja adalah positif signifikan sejalan dengan hipotesis yang diajukan sehingga teruji tingkat kebenarannya. Adanya pengaruh positif signifikan kompetensi terhadap motivasi artinya variabel kompetensi mampu memberikan perubahan atau peningkatan secara nyata terhadap variabel motivasi di Instalasi Wing Amerta RSUP Sanglah Denpasar. Pengaruh variabel kepemimpinan terhadap kinerja memiliki standardized estimate (regression weight) sebesar 0,298, dengan Cr (Critical ratio $=$ identik dengan nilai t-hitung) sebesar 2,261 pada probability 0,024. Nilai CR 2,261 > 2,000 dan Probability $=0,024<0,05$ menunjukkan bahwa pengaruh variabel laten kepemimpinan terhadap variabel laten kinerja adalah positif signifikan sejalan dengan hipotesis yang diajukan sehingga teruji tingkat keberannya. Adanya pengaruh positif signifikan kepemimpinan terhadap kinerja artinya variabel kepemimpinan secara nyata mampu memberikan perubahan atau peningkatan terhadap variabel kinerja di di Instalasi Wing Amerta RSUP Sanglah Denpasar. Pengaruh variabel kompetensi terhadap kinerja memiliki standardized estimate (regression weight) sebesar 0,495, dengan $\mathrm{Cr}$ (Critical ratio = identik dengan nilai t-hitung) sebesar 3,543 pada probability ***. Nilai CR 3,543> 2,000 dan Probability $=* * *<0,05$ menunjukkan bahwa pengaruh variabel laten kompetensi terhadap variabel laten kinerja adalah positif signifikan sejalan dengan hipotesis yang diajukan sehingga teruji tingkat keberannya. Adanya pengaruh positif signifikan kompetensi terhadap kinerja artinya variabel kompetensi secara nyata mampu memberikan perubahan atau peningkatan terhadap variabel kinerja di di Instalasi Wing Amerta RSUP Sanglah Denpasar. Pengaruh variabel motivasi kerja (MOT) terhadap kinerja (KIN) memiliki standardized estimate (regression weight) sebesar 0,027, dengan $\mathrm{Cr}$ (Critical ratio $=$ identik dengan nilai $\mathrm{t}-$ hitung) sebesar 0,205 pada probability 0,837. Nilai CR 0,205 2,000 dan Probability =0,837 $>$ 0,05 menunjukkan bahwa pengaruh variabel laten motivasi kerja (MOT) terhadap variabel laten kinerja (KIN) adalah positif tidak signifikan sejalan dengan hipotesis yang diajukan sehingga teruji tingkat keberannya. Adanya pengaruh positif signifikan motivasi terhadpa kinerja artinya variabel motivasi secara nyata mampu memberikan perubahan atau peningkatan terhadap variabel kinerja di di Instalasi Wing Amerta RSUP Sanglah Denpasar. Peran kepemimpinan dalam memediasi pengaruh kepemimpinan terhadap kinerja pegawai di Instalasi Wing Amerta RSUP Sanglah Denpasar menunjukkan bahwa mendapatkan t hitung sebesar $=0,208$ dan signifikan dengan nilai $0.417>0.05$ maka dapat disimpulkan bahwa ada 
pengaruh positif yang tidak signifikan mediasi motivasi kerja antara pengaruh kepemimpinan terhadap kinerja pegawai. Peran motivasi dalam memediasi pengaruh kompetensi terhadap kinerja pegawai di Instalasi Wing Amerta RSUP Sanglah Denpasar atas menunjukkan bahwa mendapatkan thitung sebesar $=0,207$ dan signifikan dengan nilai $0.417>0.05$ maka dapat disimpulkan bahwa ada pengaruh positif tidak signifikan mediasi motivasi kerja antara pengaruh kopetensi kerja terhadap kinerja pegawai. 


\section{DAFTAR PUSTAKA}

Ardana, I.K., Muljati, N.W., Mudiartha, I.W. (2012). Manajemen Sumber Daya Manusia. Yogyakarta: Graha Ilmu.

Dewi, N.K.Y.W., and Darma, G.S. (2019). Strategi Investasi \& Manajemen Resiko Rumah Sakit Swasta di Bali, Jurnal Manajemen \& Bisnis, 16 (2): 110-127.

Dewi, A.A.I.S., and Darma, G.S. (2017). Proses Rekrutmen, Seleksi, Pelatihan, Penempatan dan Kinerja Karyawan, Jurnal Manajemen \& Bisnis, 14 (1): 1-18.

Ferdinand, A.T. (2014). Structural Equation Modeling Dalam Penelitian Manajemen, Edisi ke 5. Semarang: Fakultas Ekonomi dan Bisnis Universitas Diponegoro

Fu'ad, E.N. (2016). Pengaruh kompetensi dan motivasi terhadap kinerja manajer koperasi di kabupaten Jepara. The 3th university research colloquium.

Giantara, I.P.G. (2017). Pengaruh Kepemimpinan, Motivasi, dan Kepuasan Kerja terhadap Kinerja karyawan PT JasaMarga Bali Tol, Jurnal Ekonomi \& Bisnis, 4 (2): 101.

Halim, T., and Darma, G.S. (2019). Faktor Penentu Kesuksesan Web-Based Appointment System di Rumah Sakit, Jurnal Manajemen Bisnis, 16 (4): 1-19.

Hendhana, S., and Darma, G.S. (2017). Service Quality Rumah Sakit dan Efeknya terhadap Patient Satisfaction, Perceived Value, Trust, dan Behavioral Intention, Jurnal Manajemen \& Bisnis, 14 (1): 37-55.

Kumarawati, R., (2017). Pengaruh Motivasi Terhadap Disiplin dan Kinerja Pegawai Pada Sekretariat Daerah Kota Denpasar, Jurnal Ekonomi \& Bisnis, 4 (2): 63-75.

Kurniadi, A. (2013). Manajemen Keperawatan dan Prospektifnya. Jakarta: Badan Fakultas Kedokteran Universitas Indonesia.

Kurniadi. (2013). Manajemen Keperawatan dan Prospektifnya (Teori, Konsep, Dan Aplikasi).

Jakarta: Badan Penerbit Fakultas Kedokteran Universitas Indonesia

Mashuri, I. (2014). Mengelola Perpustakaan Sekolah Problem dan Solusinya. Yogyakarta: Naila Pustaka.

Mondiani, T. (2012). Pengaruh Kepemimpinan Transformasional Dan Kompensasi Terhadap Kinerja Karyawan PT. PLN (Persero) UPJ Semarang, Jurnal Administrasi Bisnis, I (1). Muogbo U.S. (2013). The Impact of employee Motivation On Organisational Performance (A Study Of Some Selected Firms In Anambra State Nigeria), The International Jornal Of Engineering And Science (IJES), 2 (7).

Putra, I.P. (2017). Pengaruh Pelatihan, Motivasi, Lingkungan Kerja dan Motivasi Terhadap Kinerja Karyawan Pada Rumah Makan Warung Mina, Ekonomi \& Bisnis, 4 (2): 89. 
Setyawati, T., and Darma, G.S. (2018). Efektifkah Experiential Marketing di Sebuah Rumah Sakit ?, Jurnal Manajemen \& Bisnis, 15 (1): 160-175.

Triyanto, E. (2014). Pelayanan Keperawatan Bagi Penderita Hipertensi Secara Terpadu. Yogyakarta: Graha Ilmu.

Wiandari, I.A.A., and Darma, G.S. (2017). Kepemimpinan, Total Quality Management, Perilaku Produktif Karyawan, Kinerja Karyawan dan Kinerja Perusahaan, Jurnal Manajemen \& Bisnis, 14 (2): 61-78.

Widiari, I.A.R., and Darma, G.S. (2019). Evaluasi Kinerja Pegawai Kontrak Melalui Tujuh Kompetensi Spencer Pada Pelayanan Denpasar Sewerage Development Project (DSDP), Jurnal Ilmiah Manajemen \& Bisnis, 2 (2): 360-367.

Widiatmika, P.H., and Darma, G.S. (2018). Good Corporate Governance, Job Motivation, Organization Culture Which Impact Company Financial Performance, Jurnal Manajemen \& Bisnis, 15 (3): 82-99.

Widiastra, I.K., and Darma, G.S. (2015). Komitmen, Kepuasan Kerja, Organizational Citizenship Behavior dan Kinerja Pegawai Kontrak, Jurnal Manajemen \& Bisnis, 12 (2): $214-241$.

Winarta, K.A.S., and Darma, G.S. (2018). Strategi Pemasaran Bayi Tabung di Bali, Jurnal Manajemen \& Bisnis, 15 (4): 82-91.

Yudiastra, P.P., and Darma, G.S. (2015). Pengaruh Penggunaan Teknologi Informasi, Disiplin Kerja, Insentif, Turnover Terhadap Kinerja Pegawai, Jurnal Manajemen \& Bisnis, 12 (1): 156-172.

Yudistira, C.G.P., dan Siwantara, I.W. (2012). Pengaruh Gaya Kepemimpinan Transformasional Ketua Koperasi dan Kompetensi Kecerdasan Emosional Manajer Koperasi Terhadap Kepuasan Kerja dan Kinerja Manajer Koperasi di Kabupaten Buleleng, Jurnal manajemen, Strategi Bisnis dan Kewirausahaan, 6 (1): 99 - 108. 